\title{
Current Security Status and Development Tendency of Packaging Materials for Infant Food in China
}

\author{
Liyan Gao \\ Institute of Art and Fashion, Tianjin Polytechnic University
}

\begin{abstract}
In recent years, with the rapid development of national economy, people are improving their living standards day by day and paying growing attention to food safety. Food cannot be separated from packaging, and security problems caused by food packaging are increasingly serious. As child is a special vulnerable group among consumers, food safety problems concerning with them even could not be ignored. For the past few years, infant food security incidents have been frequently exposed, leaving painful tragedies for children, families and the society, and food packaging problems have become an "invisible killer" that infringes the physical and mental health and safety of children. This article conducts a detailed analysis to the current security status of food packaging materials of infant food in China, which are illustrated from three aspects: the inherent safety problems of food packaging materials of infant food, security issues brought by lack of standardization of packaging material production, and safety problems due to incompletion of the detection system and related laws for packaging materials. This text also suggests strategies for the security problems of infant food packaging materials, and makes prospects for its future development. (Abstract)
\end{abstract}

Keywords-infant food; packaging materials; security issues (key words)

\section{INTRODUCTION}

With the improving of living standards, people are increasingly valuing life's basic necessities of themselves and their family. The safe handling of food is nearly an issue concerned and attached importance to by everybody. Packaging material plays a vital role in food safety, which could protect the food against outside pollution and ensures that the moisture, composition and quality would not change. At the same time, however, chemical components of packaging materials themselves may impact the safety of food which, for example, may be transferred to food through heating or illuminating. If the transfer volume exceeds the standard, food safety would be strongly impacted. And due to the inherent physiological characters of children, hypoimmunity and weak resistance to outer pollution, irreversibly serious results are more easily to come. For the past few years, infant food is occupying a more and more large proportion in the whole food industry. However, it is unable to recognize potential hazards of food, such as the selected materials, decorative designs and integral construction of the packaging for infant food, all of which are likely to have an influence on children.

\section{CurRent SECURity Status OF PACKAGING MATERIALS OF INFANT FOOD}

\section{A. Inherent Safety Problems of Packaging Materials for Infant Food}

The packaging materials of food are usually called "special food additives", which is the "invisible killer" to food safety to a certain extent. [1]Current packaging materials of infant food in our country are mainly plastics, papers, metal, composite materials, ceramics, wood, glass, cloth bags, gunny bags, and bamboo. [2]The most widelyused and practical material is plastics, paper, metal and glass, and the food packaging materials made from these textures have become four main pillar materials in packaging industry, but misusage of these materials may cause food safety problems.

1) Plastic Food Packaging Materials: Plastic packaging materials have been widely used because they are lightweight, waterproof and moisture proof, easily processed, portable, corrosion resistant and cheap, which have become a main packaging materials. Plastic is actually a kind of highmolecular material, which is normally divided into natural high-molecular material, modified high-molecular material, and synthetic high-molecular material. However, highmolecular material is not a homogeneous material, which would be added with plasticizer, colorant, filler, stabilizer, and lubricant. These additives are toxic of various degrees, which may transfer to infant food through touching, leaving their content out of limits. Plastic packages themselves may decompose with highly toxic substances after heating, illuminating, and microwave irradiation, thus plasticpackaged food should generally not be heated directly. For example: for plastic resins, the monomer for producing polyvinyl chloride (PVC) and polyvinylidene chloride (PVDC) is obvious mutagenic; PVC plastic packaging materials, when heated over $50^{\circ} \mathrm{C}$, would slowly separate out hydrogen chloride gas $(\mathrm{HCl})$ that is heavily toxic to human body, and would be greatly influential to the growth and development of children. Meanwhile, for other plastic materials, such as styrene monomer in polystyrene resin and acrylonitrile monomer in acrylonitrile plastic are strong 
cancerogenic substances, which have destructive effects on hepatocytes and so on.

2) Paper Food Packaging Materials: Compared to plastic products, paper products have less pollution to environment, are easily to decompose and cheap to get, which is the most traditional packaging materials for food. However, during the papermaking process, some additives, like bleach, colorant, and permeability-reducing agent bring hidden safety hazards to paper packaging materials; otherwise, for uncleanness in raw materials of papermaking themselves, some conscienceless manufacturers utilize recycled materials for papermaking, thus food packaging materials they produced contain large amount of impurity that leaving residuals of heavy metals and chemical components, and pollutions of microbes. Paper packaging materials may also have pollutants of fluorescent chemicals and oil ink. Due to the inherent physiological characters of children, hypoimmunity and weak resistance to outer pollution, lack of judgment for things and self-protective awareness, food safety issues are more easily to come, so once children eat the food packaged by those polluted paper, they are most likely to have disease.

3) Metal Food Packaging Materials: Metal wrapping materials are greatly thermal conductive, heat resistant and tolerant to shock, with good performance of mechanical deformation for machine-shaping easily so as to increase producing efficiency to a large extent. Therefore, they attract more and more preferences. Currently, the most widely used ones for food packaging materials are respectively aluminum and iron. As it is well known for everybody, pure aluminium products are very soft thus they are usually made into aluminium alloy for food packaging materials. The main safety problem lies in the impurities existing during aluminium casting and recycling. Currently, raw materials of aluminium used in our country are with high purity with less poisonous metals. However, recycled aluminium is uncontrollable for impurities and poisonous metals which would easily give rise to food pollution. Ironwares have less chemical stability and weak acid resistance, being easily corroded by acidoid, with metal ions separated out affecting the taste of food, some of which are even more likely to lead the metal ions inside children's bodies out of limits. Meanwhile, due to more hermetic tightness of packaging materials made from metal materials, once the food remains airtight, some anaerobes inside the food may reproduce in quantities, especially in some food containing high animal proteins where anaerobes are possible to proliferate, which would be harmful to children. Therefore, food packaged with metal materials should be used within its prescribed time limits.

\section{B. Security Problems Brought by Nonstandard Production} of Packaging Materials for Infant Food

Currently, the number of companies in food packaging production is up to over $6,000^{[3]}$ in China, and due to this big figure, there is a fact that various company scales and corresponding product qualities are intermingled. Some conscienceless merchants even use inferior raw materials and recycled waste plastics to lower down the cost of production. Moreover, for most domestic food manufacturers, they adopt outsourcing packaging products, while related packaging manufacturers are general-type companies, whose production environments and sanitary conditions are hardly to ensure the safety of the products.

Both the adhesives and printing ink for packaging materials need benzene homologs and derivates as solvent, which are widely known for their harm for human body and listed as carcinogenic and dangerous chemicals with heavy toxicity by FDA, USA. This kind of solvent, through touching and inhalation, would enter into skin or blood vessels to damage neural system and hematopietic function of human body, and even causing leukemia with excessive suction volume or long-term touching. And due to the strong adsorption power of ink pigment, benzene solvents are hardly wiped out. When processing paper products into infant food packaging, even tiny residuals could be adsorbed by the food, resulting in severe food contamination, leading to permanent harm to the human health of children. Till now, our country has not got specialized oil for food packaging; therefore the security problem that benzene exists in food packaging is still very fearful. However, in some Europe and America countries, it has been regulated that raw materials containing benzene should not be used in food packaging. In China, on account of the high cost of nonbenzene oil ink, manufacturers that are able to use nonbenzene packaging are sparse, coupled with the impossibilities for customers to aware or identify those hidden security problems, leading to critical security issues of packaging materials of infant food in our country. In consequence, related laws and regulations concerned with food in our country are to be strengthened.

\section{Faultiness in Testing System and Related Laws of Packaging Materials of Infant Food}

At present, the detection means and equipments for food packaging in our country have been inadequately perfect. Normally, it is necessary for the detection to use special instruments and equipments by special organizations, which is a long-drawn process and with tedious procedures. All of these block the possibility of a fast and efficient detection of food packaging materials. At the same time, there are fewer laws and regulations concerned with infant food packaging materials in our country, which are incomprehensive in design and have not been thoroughly popularized to the public, thus people are weak in the legal consciousness in this aspect and as a result are unable to protect their legal interests effectively. Secondly, the reaction mechanism of related departments in our country is not yet complete. When customers raise questions for safety and sanitation of food packaging materials, these questions are not fed back to relevant authorities like governments to take measures 
immediately; if the material has no impacts on food safeties, the department concerned should give clarifications in time. As a result of the negligence of related departments, when hazardous packaging materials flow into the market, we should recall them right now against damages, and stop the production and call to interrelated responsibilities. We are still deficient in these aspects, which should be paid adequate attentions.

\section{STRATEGIES COPING WITH SECURITY PROBLEMS OF PACKAGING MATERIALS OF INFANT FOOD}

In order to deal with current safety problems of packaging materials for infant food, people should recognize the security issues fundamentally. Therefore, the prior issue to deal with food safety problems is to strengthen publicity and education and enhance all people's awareness. Schools, public places, and media should be utilized to publicize the knowledge and identification methods of packaging materials for infant food, exposing security incidents that appear and trace them for handling. We should raise the civil awareness for food safety, and parents should maintain strict standards that, before children eating the food, parents should check whether the packaging are broken, whether vacuum packages are leaking, whether within the time limit for edibility, and whether there are standards and notices on the packages. The civil awareness of food safety should be enhanced through publicity and education. Next, for the selection of packaging materials of food, nontoxicity and innocuity must be realized in order to make sure that packaging materials are not polluted during the processes of production, packaging, and transportation. Moreover, our country should reinforce the management of related packaging materials of food containers, set corresponding sanitary standards, establish health framework system, draw up relevant safety evaluation system, and need to modify and maintain the above standards in accordance to the actual circumstances at fixed period. The enforcement of those regulations and standards could further guarantee the safety of infant food packaging.

\section{Future DeVElopment Tendencies of PACKAging MATERIALS OF INFANT FOOD}

Along with the promotion of civil qualities and the attention to children security, more and more infant food start to take a green food route, with people beginning the study of nontoxic, harmless, green, and secure materials to produce the packages of infant food. For example, currently an advanced edible packaging material comes into style, which is processed into shaping from a material that is edible and beneficial to children's growth. This material contains cod-liver oil and calcium that are necessary substances for children's growth, which would not be harmful to children, but on the contrary contribute to their health growth. This pre-formed material performs better in damp resistance, elasticity, and toughness, sealing moisture while preventing oxygen permeating, which is a most reasonable packaging material. On the other hand, this edible packaging also remit current environmental crisis, ${ }^{[4]}$ which is nontoxic, innocuous, pollution-free and waste-free advantages, thus it is promising in the market. However, as it is costing, this material has not been widely used, but with the attractions of more and more attention by packaging fields of infant food and drugs, edible materials will certainly become a main trend in the development of food industry in the world. Under the precondition of security, the future food packaging materials will draw much attention on functionalization, such as some barrier packaging materials and thermal resistant packaging materials are developing promptly.

\section{REFERENCES}

[1] LU Linxue, "On the Security of Packaging Design of Infant Food”, Packaging Engineering, vol. 32, pp. 8-14, 2011

[2] ZHANG Jianhaoz, "Food Packaging”, China Agriculture Press, 2002

[3] LU Yanyan, "Opinions on the Management of Food Packaging Materials in China”, Chinese Jounal of Health Inspection, vol. 5, pp. 384-386, 2008

[4] ZHANG Ruizhuo, "A Safety Study on Packaging Design of Infant Food”, Shijiazhuang: Hebei University, 2008 